\title{
Export Sophistication Index of Manufacturing Industry in China: A Literature Review
}

\author{
BAI Yang \\ School of Economics \\ Central University of Finance and Economics, Beijing \\ China
}

\begin{abstract}
The export sophistication index of products has always been the focus of China's export trade and industrial transformation and upgrading. Around the related problems of export sophistication index, several methods of measuring export sophistication index have been developed from different perspectives in existing literature. The author divides them into three categories: product technology level perspective, income level hypothesis perspective and vertical specialization division perspective. In addition, empirical literature finds several factors that affect the export sophistication index, including human capital accumulation, FDI, institutional quality and financial development level. This paper systematically reviews the development of China's export sophistication index, and discusses the existing problems and possible improvements in the future. Finally, this article will point out a few issues that may need to be addressed in the future.
\end{abstract}

Keywords: Sophistication index; Measurement method; influencing factors

\section{Introduction}

With the sustained and rapid growth of China's economy, the role of international division of labor is becoming more and more important. How to successfully achieve industrial transformation and upgrading and accelerate the development of products to high-tech content will determine China's future position in international division of labor. In this context, it is of great theoretical and practical significance to study the sophistication index of China's manufacturing exports. Since Finger \& Kreinin (1979) put forward the Export Similarity Index (ESI), the measurement of technology content of a country's export products has gradually attracted the attention of academia. The study of China's problems has gradually attracted the attention of scholars in the new century. Guan Zhixiong (2002) based on the hypothesis that the products with higher added value are from high-income countries, used the method of direct value-added to measure the level of technology complexity index (TSI) of Chinese export products. From this point of view, domestic and abroad scholars have gradually begun to pay attention to the export sophistication index of China, and a considerable number of research results have been produced, including the measurement of indicators, influencing factors and so on. Based on it, this paper systematically reviews the domestic and foreign literature on the mainstream measurement methods and the influencing factors of export sophistication index in China, summarizes and prospects the current research. The content of the article is arranged as follows: The second part introduces the theoretical basis of the export sophistication index. The third part reviews the development of the measurement methods about export sophistication index from the perspective of industrial hierarchy, income level and vertical specialization. The fourth part summarizes the key factors affecting China's export sophistication index based on existing empirical literature. The fifth part is conclusions and prospects.

\section{Correlation Theory}

David Ricardo puts forward the theory of comparative advantage (is also known as "comparative cost trade theory") in his book "Principles of Political Economics and Taxation". He believes that the basis of international trade is the relative difference of production technology between participating countries. This difference mainly reflects the relative cost of products. In other words, countries with higher productivity level have higher income level, mainly rely on capital-intensive and technology-intensive industries, and have comparative advantages in products with higher technology level; countries with lower productivity level have lower income level, mainly rely on labor-intensive industries, and comparative advantages in products with lower technology level. A country's export decision-making should follow the principle of "taking the two advantages as the most important and taking the two disadvantages as the least", so comparative advantage is the basis of the formation of a country's export technology structure. The core content of factor endowment theory (which also known as "H-O theory") is that the foreign trade of a country (or a region) should follow the principle of exporting products produced by relatively abundant factors and importing products produced by relatively scarce factors. Technology can be regarded as a factor of production. 
According to the logic of factor endowment theory, if a country has a high degree of technology-intensive and a relatively concentrated technology-intensive industry, and can produce products with high technology content, then it should mainly export products with high technology complexity and import products with low technology complexity. In the 1960s, the theory of intra-industry trade developed gradually. Based on the hypothesis of "imperfect competitive market" and "return on scale", the theory is mainly used to explain the two-way trade between developed countries in importing and exporting the same goods (including intermediaries) in a certain time. According to the theory of intraindustry trade, the conclusion is that the technological level between countries should be convergent. In the 1990s, the development of intra-product division theory successfully explained the paradox of those developing countries that lack technological development but export high-tech products. The emergence of multinational enterprises in developed countries has provided opportunities for developing countries to integrate into the global value chain system. In order to ensure cost advantages, multinational enterprises have laid out low-tech links such as processing and assembly in the production process in developing countries' markets, because developing countries have lower labor costs, while retaining their manufacturing and $\mathrm{R} \& \mathrm{D}$ core components in the production process. In this way, developing countries usually import high-tech intermediate products for processing, assembling and re-exporting, resulting in the illusion that their export products have high technological complexity ("Rodrik Paradox"). The new trade theory represented by Melitz (2003) heterogeneous enterprise model provides a new research idea for export trade research. The theory holds that the change of a country's export technology structure is realized by the two paths of "intensive margin" and "expanding margin".

\section{Evolution of Measuring Method: Inheritance and Innovation}

Export sophistication index can reflect the structure of manufacturing industry behind a country's export products to a certain extent because of its unique measurement method. Therefore, whether it is to study the problems of industrial transformation and upgrading or export trade, it has been favored by scholars. At present, the measurement of sophistication index of export products is mainly carried out from three perspectives: industry level perspective, income level perspective and vertical specialization perspective.

\subsection{Viewpoint of Product Technology Level}

For the measurement of export sophistication index, some scholars take industrial grade division as a starting point. Firstly, the industry is divided into different technological levels, so that the technological level of a country's export products can be further calculated. OECD (1996) divides manufacturing products into high technology products, medium-high technology products, medium-low technology products and low technology products according to the R\&D of the industry. On this basis, Lall (2000) divides exports into five categories and ten grades: primary products, resource-intensive manufactures, low-tech manufactures, medium-tech manufactures and high-tech manufactures, taking fully into account factors such as input of production factors, technological activities, economies of scale, barriers to entry and learning effects. The advantage of this method is that it is easier to calculate and compare the complexity of a country's export products after the division of industries, and the results are more acceptable. Qi Junyan (2006) based on the research of Guan Zhixiong (2002) and Lall et al (2000, 2005), by comparing the technological structure of exports between China and Korea, found that the overall export structure of Korea is closer to that of developed countries, and the gap between China and Korea tends to increase.

With the continuous extension of the global industrial chain, the production division of countries tends to be refined, and the products produced need to import so many intermediate products from other countries. The method of Lall (2000) has been questioned by academic circles. Firstly, vertical specialization in industry makes many of the high-tech products that developing countries may export only engage in assembly, and the export sophistication indexof their products is not high. For example, for IT industry with obvious modularity characteristics, developing countries are exporting IT products, but they are only engaged in assembly. The core components of products still need to be imported from technology exporting countries in the form of intermediate products, so the technology content of their export products is not high, resulting in the illusion of "technological upgrading". Using this indicator to measure the complexity of developing countries' exports may be overestimated. Secondly, the sophistication index of products of the same industry in different countries is also very different. For example, although the textile industry belongs to lowtech products, textile products (luxury goods) in many European countries have high technology content and added value, compared with China's textile products, the technical content is lower.

\subsection{The Perspective of Income Level Hypothesis}

The research from the perspective of income level is based on the logical starting point of "the higher the income country is, the higher the technology content of its exports" to construct the export sophistication index. Most of the current studies are based on Michaely's (1984) research, which are further improved by adjusting assumptions and improving the measurement accuracy of indicators. 
Finger, Kreinin (1979) put forward the Export Similarity Index (ESI) to describe the change of export technology structure of a country (region). Subsequently, Michaely (1984) proposed the Trade Specialization Indicator (TSI) to analyze the export sophistication index of a country (region). This index assumes that the higher the productivity of a country (region) is, the higher the technological complexity of its export products. The logic behind this index derives from Ricardo's comparative advantage theory. Ricardo put forward the theory of comparative advantage in his book "Principles of Political Economy and Taxation". He believed that every country should concentrate on producing and exporting products with comparative advantage. Based on this, Michaely constructs an index to measure the export sophistication index of a country by multiplying the weighted average of the per capita GDP of the country that produces the commodity by the proportion of the export volume of a country (region) to the total export volume of that commodity in the world. Guan Zhixiong (2002) assumed that "the products with higher added value are more from high-income countries" and used the direct value-added method to calculate the height and deviation of a country's export structure by multiplying the result of the per capita GDP of the exporting country with the weight of each country's export share of the product in the world market. By comparing the export technology content structure of East Asian countries such as China and Japan, it is found that the technology content of China's exports has increased rapidly, but there is still a gap with Japan and other countries. Fan Gang et al. (2006) improved the research of Guan Zhixiong (2002). The indirect value-added method of product technology (i.e. the principle of value-added of display technology) was used as the theoretical basis for identifying the value-added of trade products. The sum of the indicators of one country's comparative advantage (RCA) was used as the weight instead of that of Guan Zhixiong (2002). The RTVindex was constructed by multiplying the per capita GDP of the exporting country. By constructing "Competitive Complementarity Index" and "Competitive Pressure Index", using "Technology Height Curve" and combining with the classification analysis of high and low technology of trade products, we find that the technology content of China's export products has been continuously improving, and the export structure has changed from low technology to medium technology.

Hausman et al. (2007) improved it which based on Michaely's (1984). The proxy variable of "product-related income level" (PRODY) was proposed as "product labor productivity". Then the index of measuring product technical complexity (Export Sophistication Index) was obtained, and the EXPY index of measuring economic and trade basket productivity level was put forward. The idea of this method is to calculate the export sophistication index of all tradable commodities separately, and then weighted sum the export sophistication index of a country. The specific expressions are as follows: Firstly, the export sophistication index of commodity $\mathrm{K}$ in export trade sub-item is calculated. Among them, $P R O D Y_{k}$ denotes the export sophistication index of commodity $\mathrm{k}, x_{j k}$ denotes the export of commodity $\mathrm{K}$ of national $\mathrm{j}, X_{j}$ denotes the total export of national $\mathrm{j}$, and $Y_{j}$ denotes the per capita income level of national $\mathrm{J}$.

Then, the export sophistication index of a country $\mathrm{j}$ is calculated.

$$
E X P Y_{j}={ }_{k} \frac{x_{j k}}{X_{j}} P R O D Y_{k}
$$

Among them, $E X P Y_{j}$ denotes the export technology complexity of country J.The measurement method of Hausmann et al. (2007) has been widely used in academic circles and further improved and revised based on it. Rodrik (2006) found that the export sophistication index of China and India was significantly higher than that of countries or regions with similar development level, which triggered a debate on export sophistication index in academic circles, also known as "Rodrik Paradox". Countries (or regions) with similar per capita income levels have obvious differences in export sophistication index. However, Xu B.(2010) argues that Rodrik's(2006) approach overestimates the export sophistication index of China. His measurement method is also based on the Hausmann method and the product quality is revised to construct the product quality to modify the export sophistication index.In addition, Van Assche \& Gangnes B. (2008) found that there is no "Rodrik Paradox" in China's electronics industry. Du Xiuli\& Wang Weiguo (2007) revised the Hausmann et al (2007) method by adjusting the hypothesis to "the higher (lower) income countries produce a class of products, the higher (lower) technology content of the products" and standardizing one country's exports accounted for the world's total. The proportion of export volume leads to the technical content (ETC) of a country's products. A new analytical method for the technical structure of export trade is proposed, and the technological structure changes of China's export trade from 1980 to 2003 are re-estimated.

They found that since the reform and opening-up policy, the overall level of China's export trade has greatly improved and showed a weak convergence trend to the world level; the technical structure of export trade has not improved significantly, but the distribution of technology in export trade has changed greatly. Subsequently, Yao Yang \& Zhang Ye (2008) also designed DTC $_{j}$ which based on Hausmann et al (2007). The domestic technology content (DTC) of 
products is obtained by stripping the share of import contribution in the technical content of intermediate inputs. Using the input-output table to measure the technological content of exports in China, Jiangsu and Guangdong Province. They believe that the decline of domestic technological content of Chinese exports may be a temporary phenomenon. Yang Rudai\& Yao Yang (2008) redefined the technical complexity of trade products and the technical content of a country's export products, and put forward the concept of "limited catch-up". Through empirical analysis, it is found that the technological content of China's exports keeps rising. Zhu Shujin\& Zhang Penghui (2013) constructed a composite technical content index. Their contribution is that the index includes the technical complexity of the non-tradable sector using intermediate products, including the input-output table, but not in the SITC classification system, which further improves the accuracy of measurement. Ni Hongfu (2017) constructed a calculation method of technology content based on production process by referring to the principles of trade added value accounting, hidden elements and hidden pollutants. This method makes up for the simpler method Yao Yang \& Zhang Ye (2008) used to deduct the foreign technical content of intermediate products. By calculating the level and structure of export technology content of China and other major countries with the help of global input-output table, it is found that the level of China's export technology has indeed been improved and optimized to a certain extent, and it has a tendency of weak convergence to the average level of developed countries. This conclusion is basically consistent with that of Du Xiuli\& Wang Weiguo (2007).

Obviously, Hausmann et al. (2007) is an evolved method to measure the technological complexity of a country's exports, which uses real GDP per capita as the proxy variable of labor productivity to measure the technological complexity of exports. The advantage of this method is that it can accurately reflect the export sophistication index of a country by combining the actual economic situation of a country with its export situation. This method is more accurate than Lall (2000) in measuring the export sophistication index from the perspective of industrial grade. However, its shortcomings are also obvious. Firstly, the per capita GDP of different countries around the world is quite different, and the direct calculation will inevitably lead to errors. Lall et al (2006) tried to further standardize the added value of products, and obtained a new product added value index SI (i). He found that the export sophistication index of China in 2000 was lower than that in 1990, and the relative export sophistication index of China did not increase significantly. Secondly, there are great differences in GDP per capita among different regions in different countries, which is also one of the causes of errors. Schott (2007) attempted to construct a measurement method without GDP per capita, using the calculation of the similarity between a country's exports and those of a developed country to measure the export sophistication index. He believes that the higher the similarity, the more complex the country's export technology. To some extent, Schott's method reduces the measurement error caused by regional GDP heterogeneity in China. Xu Zhi\& Wang Sihua (2013) put forward the concept of "relative complexity of neighboring areas". Based on the framework of overall dynamic distribution evolution, the morphological characteristics and dynamics of sophistication index distribution of export commodities at provincial level in China were investigated by using non-parametric estimation kernel density function. The final stable distribution of export sophistication index of commodities in provinces was discussed by using Markov Chain method. They found that the sophistication index changes of China's provinces follow the path of convergence to the neighborhood first, then gradually to the overall level, and have obvious stage characteristics and regional differences. So far, scholars have improved Hausmann et al. (2007), however, most studies generally prefer to use Hausmann's method, especially to the literature of empirical research.

\subsection{The Perspective of Vertical Specialized Division of Labor}

Hummels et al. (2001) divides a country's imports into domestic direct consumer goods and intermediate processing exports, and defines the proportion of intermediate products in total exports as vertical specialization ratio. Zhang Xiaoti \& Sun Jingwei (2006), Wen Dongwei \& Xian Guoming (2011), MengMeng (2012), Meng Qi (2013), Du Chuanzhong \& Zhang Li (2013) have all improved it which based on the analytical framework of Hummels et al. (2001). It is found that the vertical specialization degree of China's manufacturing exports is rapidly increasing, and the technical content of export products is constantly improving. The results of scholars' research are generally consistent. 


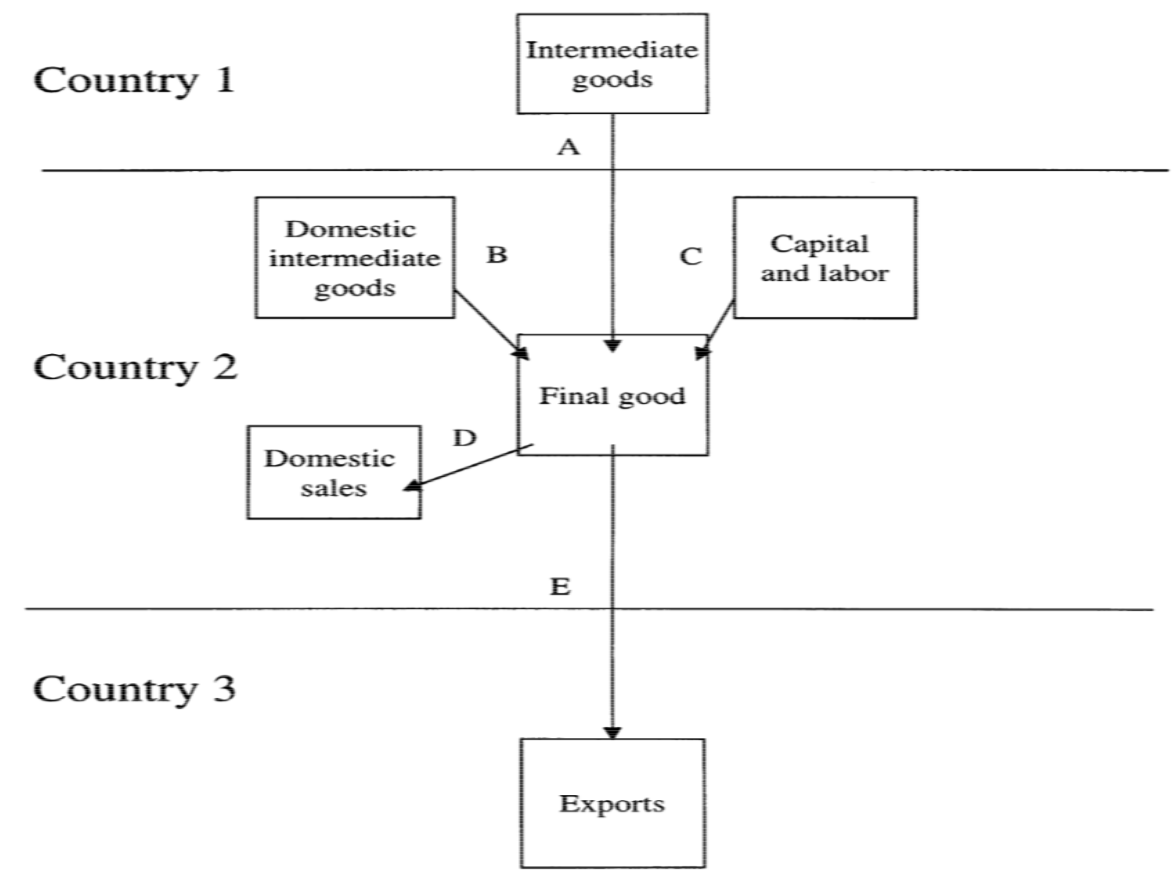

Figure 1. Vertical specialization model of Hummels et al. (2001)

Compared with the the papers which based on Hausmann et al. (2007), the vertical specialization model based on Hummels et al. (2001) has the advantages of eliminating the direct and indirect consumption of imported intermediate products. This methodisn't perfect, and it has both advantage and disadvantage. The advantage part is that it improved the precision of export technology complexity index, the disadvantage part is that it lies in the flaws in the setting of hypothetical conditions. Hummels' method uses the assumption that the quantity of imported intermediate inputs in exports and domestic sales is proportional to their share in output, which is too simple to deal with. Obviously, there is a gap between Hummels' method and the reality. This will inevitably lead to measurement errors. For example, in China's manufacturing industry at this stage, most of the imports of processing trade are intermediate inputs, and according to the above logic, the calculation will inevitably lead to underestimating China's vertical specialization degree and overestimating the technical complexity of exports.

\section{Influencing Factors from Empirical Literature}

Domestic and foreign scholars have explored the influencing factors of sophistication index. The existing literature mainly focuses on human capital investment, FDI, institutional quality, marketization and financial development level.

\subsection{Human Capital}

Thodore W. Schults, who is the founder of human capital theory, argues that "human factor is the most important factor in many factors affecting economic development." Gary S. Becker believes that "the biggest difference between human capital and material capital is that the productivity of human capital depends on the degree of human effort, and appropriate incentives can improve human productivity." Overall, the existing literature mostly supports the accumulation of human capital to promote the complexity of export technology. Scholars Wang \& Wei (2008) believe that the improvement of China's human capital level and the government's preferential tax policies for high-tech industries are the key to the improvement of export technology complexity. Stantos Paulino (2008) used sample data analysis of China, India, South Africa and Brazil to find that a country's human resources level is one of the important factors determining its export complexity. Weldemicael (2012) also draw similar conclusions. Yao Yang \& Zhang Ye (2008) also prove that the promotion of human capital plays a significant role in promoting the domestic technology content of China's exports. Wang Xiaosong et al. (2014) based on Koopman et al. (2012) estimates the domestic value added of various industries in China. It is found that human capital is an important factor affecting the technological complexity of an industry's products. In the long run, one of the main ways to improve the technological complexity of China's exports is the accumulation of human capital. Gao Mingrui (2016) explained that the government's educational financial investment could promote the export sophistication index by improving the level of regional human capital through investigating the interaction between educational financial expenditure and human capital accumulation. 
Zheng Zhanpeng\&Wang Yangdong (2017) believe that there are three main channels for the accumulation of human capital to promote theexport sophistication index. Firstly, the accumulation of human capital can improve the technological complexity of products by directly improving the labor productivity of enterprises; secondly, the accumulation of human capital can provide conditions for the adjustment of industrial structure, and then affect the export trade structure; thirdly, the accumulation of human capital provides conditions for enterprises to widely absorb foreign advanced technology and management experience, which is conducive to the realization of technological upgrading of enterprises. Improve the technical complexity of products. The provincial panel data are used to verify the reliability of the conclusions.

At present, some scholars try to explore the reverse causality between them, that is, the mechanism of the reverse effect of technological complexity on human capital accumulation. Chen Weitao et al. (2014) used Falvey et al. (2010) and Hausmann et al. (2007) for reference to construct a theoretical model of human capital investment of urban and rural labor force in China based on the background of urban and rural labor market segmentation. He found that the increase of export technology complexity can promote the improvement of human capital level in urban and rural areas, the improvement of expected return of human capital investment in the future and the increase of long-term human capital investment. The reliability of the conclusions is verified at the micro level through China Industrial Enterprise Database, China Household Income Survey (CHIPS) and World Bank (TPP).

\subsection{FDI}

The impact of FDI on technological complexity can draw different conclusions from different perspectives. First, in terms of overall impact, Amiti\& Freund (2008) argue that the processing trade of FDI and OECD countries increases the technological complexity of China's exports. Similarly, Zhu Shujin\& Zhang Penghui (2013) drew similar conclusions. They found that the technology spillover effect of FDI has a significant effect on the improvement of the composite technology content of FDI structure and domestic technology content, especially on the improvement of technology content of capital-intensive and technology-intensive industries. Wang Xiaosong et al. (2014) believed that the higher the proportion of foreign-funded enterprises, the higher the level of technology. Secondly, if we analyze it from the perspective of regional and industrial heterogeneity, the conclusions are different. Zhu Shujin \& Zhang Penghui (2013) argued that FDI did not significantly promote the technological content of capital-intensive and technology-intensive industries. Zhao Hong \& Peng Xin (2014) compared the export sophistication index of products at provincial regions and countries level, and they found that the role of inter-provincial FDI on the export sophistication index has obvious heterogeneity, but overall presented a "catch-up effect". Liu Shiqin \& Liu Houjun (2015) put more emphasis on the role of internal knowledge variables in the upgrading of export structure. Foreign-funded enterprises have insufficient R\&D investment and innovation willingness in China. Liu Sheng \& Gu Naihua (2016) believe that "absolute scale FDI" and "relative scale FDI" (i.e. FDI/GDP) can promote the sophistication index of manufacturing exports. And the empirical test proves that the phenomenon of "regional heterogeneity" of FDI's sophistication index of manufacturing exports does exist. It is found that FDI has a good promotion effect on coastal areas and eastern areas (due to good market environment, etc.), while it has a relatively poor promotion effect on inland areas or central and Western areas.

\subsection{Urbanization}

In theory, there may be two situations about the impact of urbanization on sophistication index: Firstly, urbanization promotes technological complexity. The reason is that urbanization brings convenience infrastructure for enterprises, reduces transaction costs, improves knowledge spillover among enterprises and promotes enterprise innovation. For example, the intensive highway construction in cities and surrounding areas has greatly reduced the cost input of enterprises, but also strengthened the links between enterprises, promoted innovation capacity, and increased the technological complexity of products. The improvement of technological complexity also promotes the technological innovation capability of enterprises. Liang Chao (2013) found that increasing the complexity of export technology can significantly improve the technological innovation capability of enterprises. However, there exists regional heterogeneity, and the upgrading of export technology complexity promotes the upgrading of technological innovation capability in the eastern region. Secondly, urbanization hinders technological complexity. The reason lies in the fact that urbanization has brought about population aggregation, which in turn leads to enterprises increasing the cost of living for workers, such as food and shelter; in addition, the rent and maintenance costs of factory buildings and machinery will also increase.

As far as the current research results are concerned, the conclusion supports the view that urbanization promotes sophistication index. Wang Yongjin et al. (2010) analyzed the mechanism of infrastructure affecting technological complexity within the framework of heterogeneous enterprise analysis, and measured the export technological complexity of 101 countries which based on Hausmann et al. (2007) and Xu (2007). The estimated results of 2SLS and 
system GMM also confirm that infrastructure has steadily increased the export complexity of countries. Chen Xiaohua \& Li Nidan (2017) believe that urbanization process has a significant role in promoting the export technology complexity of manufacturing industry from the national level; from the regional heterogeneity level, the total amount of upgrading technology complexity from high to low is in the east, middle and west, and the increase from high to low is in the west, middle and east, which shows that the process of urbanization in the region has a significant role in promoting the export technology of manufacturing industry. The effect of surgical complexity is positive. In addition, a part of the literature incorporates infrastructure as a control variable into the model, and the results also show that infrastructure has a significant positive effect on technological complexity, which this paper do not list one by one.

\subsection{Marketization}

Shengdan \&Wang Yongjin (2011) drew on the theoretical framework of Acemoglu et al. (2007) and developed a theoretical model of the micro-mechanism of the effect of marketization on provincial regional industrial growth. They found that areas with higher marketization were conducive to the rapid development of industries with higher technological complexity. Liu Sheng \& Chen Xiuying (2016) explained the mechanism of the degree of marketization affecting the technological complexity of manufacturing exports from five aspects: the relationship between government and market, the development of non-state-owned economy, the development of factor market, the development of product market, the development of intermediary organizations and the legal economy. They put forward the theoretical hypothesis that "the process of marketization promotes the technological complexity of manufacturing industries", and used the provincial panel data to analyze the mechanism. It is verified at the national level and the sub-regional level respectively.

\subsection{Institution}

Levchenko (2004) believes that the products with high sophistication index are based on complex production relations and technologies, so a good institutional environment is necessary. In other words, countries with higher institutional quality are guarantees for the intensive existence of enterprises (or industries) producing high-tech and complex products. Research by Berkowitz \&Pistor (2006) also confirms that countries with higher institutional quality tend to export products with higher sophistication index and import products with lower sophistication index. Costinot (2007) argues that countries with higher sophistication index have higher degree of specialization and uncertainty in contract execution. Therefore, only those countries with better human capital and institutional environment have comparative advantages to produce products with high sophistication index. Krishna \& Levchenko (2009) found that due to the lack of good institutional environment and human capital, less developed countries often are at the low end of the global industrial chain to produce products with lower sophistication index. Low-tech industries tend to be volatile, which to some extent explains the reasons for economic volatility in less developed countries. Dai Xiang \& Jinbei (2014) discussed the relationship between system quality and export technology complexity from the perspective of intraproduct international division of labor. They use the three indicators of political risk index (PR), economic risk index (ER) and financial risk index (FR) in the database of International Country Risk Guide (ICRG) as proxy variables of system quality. Through OLS and system GMM estimates, they find that system quality indeed promotes the relationship between export sophistication index. Zhang Yu \& Dai Xiang (2017) used similar methods to analyze the relationship between FDI and system quality and service export complexity, and reached similar conclusions.

From this point of view, a sound system is an important guarantee to promote economic development, and its role is particularly evident in industries with higher quality of export dependence system. Acemoglu et al. (2007) pointed out that the quality of the institution will affect the country's trade model, and the specific path is different systems to promote enterprises to adopt different technological choices. Countries with better institutional quality tend to produce technology-intensive products with comparative advantages, and then the export share of technology-intensive products is higher. On the contrary, countries with poor institutional quality have comparative advantages in the production of low-end labor-intensive products. Their industries are mainly processing and assembly industries, and their export share of low-tech products is higher. Therefore, the difference of system quality is the key factor leading to different countries'trade patterns. Nunn (2007) found that countries with higher institutional quality tend to have comparative advantages in industries with higher dependence on contract quality, thus showing relatively more exports. Ara(2013) combines institutional quality with enterprise heterogeneity to construct a Ricardian general equilibrium model for analyzing North-South trade. Ara finds that the comparative advantage of institutional quality-induced is mainly embodying in the industrial sectors that are more dependent on institutional quality, which leads to a larger proportion of northern countries' export system quality-intensive products than southern countries' export system quality-intensive products. Compared to Acemoglu et al. (2007) and Nunn (2007), they had the similar conclusions. 
Taking intellectual property protection as an example, intellectual property protection can be regarded as a good system, while the industries with high concentration of intellectual property are often technology-intensive industries, and the increase of export share of technology-intensive products will obviously promote the sophistication index of a country's export. Developed areas tend to have better market environment, more technology-intensive industries and greater demand for intellectual property protection. Can we think that intellectual property protection can promote the export sophistication index in relatively developed areas? Empirical studies have not provided ample evidence to support this inference. JinXiangrong et al. (2008) found that inter-provincial differences in exports were significantly affected by the legal system and property rights protection system. A further study by Dai Zhongqiang (2014) found that uneven real intellectual property protection in China has an inverted U-shaped relationship with the export sophistication index. They argue that intellectual property protection hinders the export sophistication index in the eastern part of the economic development frontier, because intellectual property protection is more conducive to foreign-funded enterprises with technological advantages, thus aggravating technological monopoly. But we can't stop the innovation Imitation Behavior of local enterprises by strengthening intellectual property monopoly. Sweet \& Maggio (2015) also found similar findings. They believed that in low-income developing countries with technological disadvantage, premature improvement of intellectual property protection level was not conducive to the upgrading of export technology. Dai Zhongqiang et al. (2015) also tested the impact of intellectual property rights on the export sophistication index of service trade using transnational panel data, and drew a similar conclusion which using domestic data. For the global sample, there is a U-shaped relationship. However, the analysis is slightly different in regions. The developed countries show a linear relationship, while the developing countries show a "U" shaped relationship. Zhu Shujin et al. (2017) used the data of China's industrial industry to find that intellectual property rights did hinder China's export technology upgrading to a certain extent.

\subsection{Financial Development Level}

Current research results mostly support the view that financial development level promotes export sophistication index. Ferguson \& Formai (2010) have examined the role of the financial system and developed countries with cash financing systems. The proportion of exports from sectors with higher export sophistication index to total exports is higher. Qi Junyan \& Wang Yongjin (2011) constructed a benchmark model containing two countries to explain the mechanism of financial development increasing the export sophistication index of a country; and extended the model to include multicountry extension model based on the research of Acemoglu (2007) and Melitz (2010), and drew a more general conclusion consistent with the benchmark model. They believe that a country's financial development can promote the export sophistication index. The higher the export sophistication index, the more uncertain the R\&D and production of enterprises, and the more difficult it is to obtain external financing in the financial market because of its own information asymmetry. Therefore, the improvement of the degree of financial development is conducive to the financing of high-tech complex products with high uncertainty, and then promotes the overall improvement of export sophistication index of a country. The reliability of the conclusions is demonstrated by cross-country data. Qi Junyan \& Wang Xiaoyan (2016) explained the mechanism of the impact of financial development on net export technological complexity based on Romer (1990) and Lai Mingyong (2005) endogenous technological progress theoretical model and Fangyuan's (2013) five-sector analysis perspective. They believe that the better the financial development, the more beneficial it is for enterprises to expand the scale and efficiency of financing, reduce the cost of financing, improve the efficiency of production and the relevance with foreign-funded enterprises, thus promoting FDI, improving the efficiency of R\&D, and further promoting the net export sophistication index. Liu Hui et al. (2014) examined the relationship between financing constraints and export sophistication index by improving Gorodnichenko \& Schnitzer (2001) model (G-S model). They believe that financing constraints are not conducive to the upgrading of the export sophistication index of Chinese local enterprises; increasing the total export volume and marginal expansion (i.e. unit export volume) can effectively reduce the negative effects of financing constraints on the export sophistication index of local enterprises.

\section{Conclusion}

The export sophistication index of China has always been a concern of academia, and it is an important basis for judging the transformation and upgrading of China's industries. Up to now, there have been considerable literature on the measurement methods and influencing factors of export sophistication index, which has formed a useful understanding.

After nearly 40 years of reform and opening-up policy, China's export trade has developed rapidly, and its position in the global value chain has continuously improved. The gap of the export sophistication index with developed countries is gradually narrowing. Although the results measured by different methods are slightly different, the judgment of the overall trend is basically the same. With the continuous improvement of measurement methods, the accuracy is also increasing. However, due to the limitation of assumptions and data, there are still many problems. 
The sophistication index evolved which based on Hausmann et al. (2007) and its improvement methods, and this assumption that "the higher the income country is, the higher the technological content of the products it exports" has limitations. For example, the sophistication index of this hypothesis couldn't explain the Middle East oil country problem very well. These countries are high-income (per capita GDP) countries, but the technology level of their export products is not high. Because the underlying logic of this assumption is that the higher the income level (per capita GDP) of a country (or region), the higher the industrial structure and the higher the technology content of export products. However, the high income of Middle East countries is exchanged at the cost of resource export, and their industrial structure is still at a lower level than that of developed countries. Therefore, the export sophistication index under this assumption is difficult to make a reasonable explanation. The existing research improves the limitations of the hypothesis, but does not propose a more perfect solution, which may be the direction of further research in the future.

The construction of technical sophistication index lacks discussion on commodity heterogeneity. The common disadvantage of the methods used in the current literature is to assume that the sophistication index of the same kind of products exported by countries is the same, thus exaggerating the export sophistication index of developing countries in the current situation of rapid Intra-product Trade growth. Ni Hongfu (2017) explored the heterogeneity problem, but only limited to the cross-border comparison of industries. Most of the discussions on corporate heterogeneity and regional heterogeneity based on empirical literature, but they can't show in the construction of technical complexity indicators. Therefore, how to incorporate product heterogeneity into the measurement system of export sophistication index may be an important aspect of future research.

The accuracy of export sophistication index's measurement needs further improvement. First, the current method is still unable to achieve a vertical comparison of time within an industry in a country. For example, compared with the early stage of reform and opening-up policy, the automobile technology level of China's automobile manufacturing industry is quite different, which isn't reflected in the export sophistication index. Secondly, it is impossible to achieve transnational horizontal comparison of an industry. The technological content of the same product in different countries is quite different, and this difference can't be reflected in the export sophistication index. Thirdly, the technological level of the same product varies greatly because of the different technological routes. For example, in the traditional agricultural sector, there is a big gap between China and the United States in the mode of production. Similarly, for wheat production, China is labor-intensive, while the United States is capital-intensive. Therefore, how to improve accuracy may also be a direction of future concern.

\section{References}

Wang, Z. \&Wei,S.J.(2008).What accounts for the rising sophistication of China's exports?NBER Working Paper,No.13771.

SantosPaulino(2008).Export productivity and specialization in China, Brazil, India and South Africa.WIDER Research Paper.

Weldemicael, E.(2012).Determinants of export sophistication. Working Paper of the University of Melbourne.

Nunn,N.(2007).Relationship-specificity, Incomplete Contracts, and the Patten of Trade.Quarterly Journal of Economics, 122(2),569-600.

Acemoglu,D.,P.Antràs,\&E.Helpman (2007).Contracts and technology adoption.American Economic Review,97(3),916943.

Ara,T.(2013).Institutions as a source of comparative advantage.Fukushima University Working Paper, No.1306.

Sweet M.C.\&MaggioE.S.D.(2015). Dostronger intellectual property rights increase innovation?World Development,(66):665-677.

Lall (2000). The technological structure and performance of developingcountry manufactured exports 1985-1998. Oxford Development Studies, 28(3): 337-369.

Lall, Weiss\&Zhang (2006) The sophistication of exports: A new trade measure. World Development, 34(2): 222-237.

Michaely(1984). Trade, income levels, and dependence.Amsterdam: North-Holland.

Finger\&Kreinin(1979). A measure of export similarity and its possible uses. Economic Journal, 89(356): 905-912.

Rodrik(2006).What's so special about China's exports. NBER working papers No.11947.

DavidHummels,JunIshii\&Kei-MuYi(2001). Thenature and growth of vertical specialization in world trade.Journal of International Economics, 54,75-96.

Gilboy, George(2004). The myth behind China's miracle. foreign affair, Vol83, issue4.

Van A.\&Gangnes B.(2008). Electronics production upgrading: is China exceptional? Applied Economics Letters,50(2):15-49.

Xu B. (2010).The sophistication of exports: is China special?China Economic Review, 21:482-493. 
Françoise Lemoine \& Deniz Ünal-Kesenci(2007). China and India in international trade: from laggards to leaders? CEPII Working Papers, No-19.

Koopman Robert,Wang,Z.\& Wei, S.J.(2012). Estimating domestic content in exports when processing trade is pervasive. Joutnal of Development Studies,99(1): 178-189.

AmitiM.\&C.Freund.The anatomy of China's export growth policy research working paper series 4628, World Bank.

A.Levchenko(2004). Institutional quality and international trade.Working Paper.

D.Berkowitz, J.Moenius\&K.Pistor(2006) Trade, law and product complexity. Review of Economics and Statistics, 88:363-373.

Arnaud Costinot(2007). On the origins of comparative advantage.Working Paper.

Pravin Krishna\&A.Levchenko(2009). Comparative advantage,complexity and volatility. Working Paper.

Shon Ferguson\&Sara Formai(2010). Institution-driven comparative advantage, complex goods and organizational choice. Working Paper.

Peter K.Schott(2006).Therelative sophistication of Chinese exports.NBER Working Papers.

MarcJ.Melitz(2003).Theimpact of trade on intra-industry reallocations and aggregate industry productivity.Econometrica,71(6):1695-1725.

Fan, G.,Guan Z.X. \& Yao, Z.Z.(2006). Analyzing the foreign trade structure based on techonogies of traded goods.Economic Research Journal, (8):70-80.

Qi, J.Y. (2006).Research on analysis method of international trade structure based on product technology content and value addeddistribution. Modern Finance \& Economics, (8):64-68.

Qi, J.Y., Wang, Y.J., Shi, B.Z. \& Sheng, D.(2001). Financial development and export sophistication index. The Journal of World Economy, (7): 91-118.

Wang, W.G. \& Du, X.L. (2007). Tecnology structure of China's exports and their changes:1980-2003.Economic Research Journal, (7):137-151.

Yao, Y. \& Zhang, Y. (2008). Dynamic study on the upgrading of domestic technological content of China's exports: evidence from China-Jiangsu and Guangdong provinces. Social Sciences in China, (8):67-82.

Yang, R.D. \& Yao, Y. (2008). Limited catch-up and economic growth. Economic Research Journal, (8):29-41.

Ni, H.F. (2017). Dynamic changes to the technological content of China's exports and an international comparison. Economic Research Journal, (1):44-57.

Wang, Y.J., Sheng, D., Shi, B.Z. \& Li, K.W. (2010). How does infrastructure affect export technological sophistication.Economic Research Journal, (7):103-115.

Dai, X. \&Jin, B. (2014). Intra-product Specialization, institution quality and export sophistication. Economic Research Journal, (7):4-17.

Zhu, S.J. \& Zhang, P.H. (2013). The domestic technical content of China's manufacturing exports and its determinants. Statistical Research, 30(6):58-66.

Hong, S.Q. \& Liu, H.J. (2015). Research on export technical structure and evolution trend: the empirical study based on China's manufacturing export data to emerging markets. Statistical Research,33(7):71-77.

Liu,W.L., Li, L.B. \& Liu, Y.M. (2014). The impact of global value chain embeddedness on technological sophistication of China's export. China Industrial Economics, (6):83-95.

Wang, X.S., Zhai, G.Y. \& Lin, F.Q. (2014). What factors affect the technological content of Chinese export products? The Journal of Quantitative \& Technical Economics, (11):21-36.

Zhao, H. \& Peng, X. (2014). The calculation of China's export sophistication and its influencing factors.

Soft Science in China, (11):183-192.

Liu, S. \& Gu, N.H. (2016). Impacts of foreign direct investment on Chinese manufacturing exports technical complexity. Journal of Capital University of Economics and Business, 18(2):11-18.

Chen, X.H. \& Li, D.N. (2017). An empirical analysis of the impact of urbanization to China's export technological sophistication of manufacture. Journal of XidianUniversity(Social Science Edition),27(3):31-44.

Dai, Z.Q. (2014). Does the intellectual property protection enhance China's export technological sophistication? An empirical study on panel data of provinces. Studies in Science of Science, 32(12):1847-1858.

Dai, Z.Q., Liang, J.W. \& Sun, Q. (2015). Intellectual property protection, economic development and technological sophistication of service trade. Finance \& Trade Economics, (7):109-122.

Zhang, Y. \& Dai, X. (2017). FDI, institution quality and service export sophistication. Finance and Trade Research, (7):59-68.

Sheng, B. \& Mao, Q.L. (2017). Does import trade liberalization affect Chinese manufacturing export technological sophistication? The Journal of World Economy, (12):52-75.

Chen, W.T., Wang, Y.J. \& Sun, W.Y. (2017). Trade liberation, import competition and Chinese industry sophistication. Journal of International Trade,(1):50-59. 
Xu, Z. \& Wang, S.H. (2013). Dynamic evolution of export technology content in China. China Industrial Economics, (8):44-56.

Liu, Z.Q., Tong, J.D. \& Xu, J.Y. (2014). Geographic agglomeration and firm export decision-research based on technological sophistication. Industrial Economics Research,(2):73-81.

Liu, S. \& Chen, X.Y. (2016). Does the marketization process in China promote the export technological complexity of the manufacturing industries?-the empirical evidence from Chinese provience panel data. Contenmporary Economic Management, 38(6):63-68. 